\title{
INTERGENERATIONAL TRANSMISSION OF EDUCATION ACROSS EUROPEAN COUNTRIES AND COHORTS
}

\author{
Majka van Doorn \\ Social and Cultural Science, Radboud University Nijmegen, Nijmegen, The Netherlands \\ loana Pop \\ Department of Sociology, Tilburg University, Tilburg, The Netherlands
}

Maarten H. J. Wolbers

Department of Sociology, Radboud University Nijmegen, Nijmegen, The Netherlands

ABSTRACT: This article investigates the intergenerational transmission of education in 28 European countries. The main aim is to answer the following questions: (1) To what degree are parents' education and the educational attainment of their children related in different countries and cohorts, and (2) how can we explain the country-cohort variation in these effects by looking at contextual characteristics? In order to explain this variation, we focus on the degree of industrialisation, female labour force participation, the structure of the educational system and the political ideology of a country. Regarding industrialisation, we do not only take its size into account, but also the pace of the development. Multilevel estimates on 76,821 individuals nested in 250 country-cohort combinations from three waves of the European Social Survey (2002-2006) show that we cannot fully support the prediction of decreasing intergenerational transmission of education solely under the influence of industrialisation. While being an important factor that positively influences the general level of schooling for a certain cohort in a particular country, its decreasing effect of the parents' education on their children's schooling is complemented by the other interacting contextual factors, such as female labour force participation and the quality of the school system.

Key words: intergenerational transmission of education; education; comparative research; industrialisation; social mobility

\section{Introduction and research questions}

Despite the extensive body of knowledge in the field of social stratification research, several key points have not been fully addressed. 
The present article originates in the status attainment model proposed by Blau and Duncan (1967), who suggested a transition from ascriptive rules of social mobility to achievement under the influence of industrialisation. The model aims to answer questions regarding how, and to what degree, circumstances of birth condition, that is father's education and occupational status, determine an individual's social status (i.e., ascription) and to what extent this is the result of merit, in terms of educational attainment (i.e., achievement). It predicts that in modern and industrialised societies, a transition from ascription to achievement has taken place, among other things resulting in a smaller effect of family background on social status attainment of individuals over time. In this article, we limit our focus on the changing relationship between parents' education and their children's educational achievements, as a key aspect of the status attainment model, from both a cross-national and cross-temporal perspective.

One of the first large scale comparative projects that aimed at examining the developments in the relationship between family background and educational attainment was initiated by Shavit and Blossfeld (1993). They brought together individual studies in 13 industrialised countries by experts in the area of social stratification research. The design of each study was similar in most countries in terms of background variables father's education and occupation - and educational outcomes of their children as successful transitions through ordered educational levels. The main conclusion of the study is that educational equalisation was not reached in the majority of the countries analysed, and origin effects on educational transitions are still prevailing. Despite its importance for the development of the field, this comparative initiative has a major shortcoming resulting from the fact that each contributor used country specific data, with incongruence in the coding of the variables of interest. Thus, despite pointing out trends for each country, there is no possibility to assess the between country variation in the importance of the macrosocietal conditions tested: the level of industrialisation and the political ideology.

Other researchers continued in this line of investigation, by taking into account a large range of societal conditions that affect the resemblance in educational positions between generations: characteristics of the educational systems (Jonsson and Mills 1993; Kerckhoff 1995; Ballarino et al. 2009), dominant political ideology, (Ishida et al. 1995; Sieben and de Graaf 2001, 2003), social security expenditures (Jaeger and Holm 2007), the changing role of women in society (Kalmijn 1994), and industrialisation and modernisation (Muller and Karle 1993). Despite the efforts to disentangle the effects of these contextual characteristics, the results are inconclusive. Tests of these hypotheses 
in a comparative framework did not fully sustain in all countries (Muller and Karle 1993). In fact, recent comparative analyses suggest that 'the degree of association between parental education and individual educational attainment has remained constant over time in most countries' (Pfeffer 2008: 552).

Other authors conclude that the differences between countries with respect to the impact of family background on the level of education of the children are better explained by political ideology than by modernisation theory (Sieben and Huinink 2001). However, tests of political ideology theory did not find the expected lower influence of family background in social-democratic and communist regimes (Ishida et al. 1995; Sieben and de Graaf 2001). Kerckhoff $(1995,2001)$ emphasises the role of different characteristics of educational systems in mediating the relation between social origin and educational attainment. Empirical tests of the institutional differences in school systems found that they are indeed relevant in mediating intergenerational transmission of education, but there are differences between developed and developing countries (Buchmann and Hannum 2001; Pfeffer 2008). One result that continuously received confirmation is that, from a time perspective, women increased their educational attainment, with rising rates of higher education completion (Ganzeboom and Nieuwbeerta 1999). However, explanations on how mothers influence the educational outcomes of their children are, again, divergent (Kalmijn 1994; Ganzeboom and Nieuwbeerta 1999; Korupp et al. 2002).

Despite this incongruence in findings, there is no doubt that contextual characteristics of different countries and cohorts play a key role in determining the intergenerational transmission of education. However, the question is how these contextual characteristics interact with the family background and shape patterns of intergenerational educational mobility in different societies and time periods. Our approach answers this question by closely following Breen and Jonsson's (2005) remark, also referred to by Pfeffer (2008: 556): ' . . convincing explanations of, for example, crossnational variation in the origin-education or origin-destination associations are lacking', a situation that can be addressed by producing '(an) exhaustive list of the set of family resources and institutional factors that impinge on the opportunities of children, and to measure their relative importance in particular societies' (Breen and Jonsson 2005: 236). This type of approach to comparative research draws from the work of Przeworski and Teune (1970), who advanced the idea of modelling the impact of the characteristics of the social systems (in this case, countries and cohorts), by replacing the labels of these social systems with the relevant variables. The strength of this comparative approach relies on the possibility of testing whether there are systematic differences between 
the social systems and what the reasons for these regularities are, giving the opportunity to provide generalisations from a mono-contextual to a multi-contextual perspective.

Our approach contributes to the more detailed understanding of Blau and Duncan's (1967) model by following Breen and Jonsson's direction. We consider that a disadvantage of the research undertaken in the field of social stratification is that it (still) lacks simultaneous testing of the influence of the range of contextual factors on the relationship between origins and destination in a comparative setting. We do not attempt to address the full model proposed by Blau and Duncan, but we particularise by looking closely at only one aspect: The effect of parents' education on children's educational achievements as defined by their acquired educational level. We acknowledge that the association between the occupational class of origin and the occupational class of destination is also a very important part of the model. However, we consider the intergenerational transmission of education to be just as (or even more) important a topic of research, due to the fact that education, and particularly the enormous educational expansion that has taken place, is the driving force behind the assumed, increasing intergenerational social mobility in modern societies.

We aim at better understanding the interaction between individual level characteristics and the specific contexts where they manifest, by taking into account the most important categories of macro characteristics that the body of literature in the field mentions. Therefore, we aim to advance the vertical status attainment paradigm proposed by Blau and Duncan (1967), which is sometimes considered to have reached its limits (Ishida et al. 1995). Although the contextual characteristics are expected to also have direct influences on the general level of schooling of different cohorts and/or countries, we do not formulate specific hypotheses directed especially to these effects.

We use data for 28 countries that took part in three waves of the European Social Survey (2002, 2004 and 2006) and deduce hypotheses that address specifically the impact of contextual characteristics in shaping intergenerational transmission of education. Two specific research questions are formulated: (1) To what degree are parents' education and the educational attainment of their children related in different countries and cohorts? (2) How can we explain the cross country-cohort variation of the relationship between parents' education and their children's education by looking at contextual characteristics? The added value of this approach is the simultaneous testing of several macro characteristics that were found relevant within the field of social stratification research, using a large dataset of 76,821 respondents from countries that were not all previously included in this kind of analyses. We use a multilevel approach with 250 
country-cohort combinations at level two in order to disentangle the individual and contextual effects, as well as the cross-level interactions.

\section{Theory and hypotheses}

\subsection{Industrialisation}

'It has been widely acknowledged that the status attainment model [Blau and Duncan 1967] revolutionized social mobility research and, for that matter, sociology at large' (Ganzeboom et al. 1991: 286). However, as these authors note, despite the fact that the model was tested for many individual countries, few attempts were made in testing this model in a comparative framework. Researchers advanced hypotheses linking industrialisation with families' background in determining children's educational and occupational achievements: 'The hypothesis that inequality of condition causes inequality of opportunity $(\ldots)$ has considerable power for explaining the general finding that educational attainment depended on social origin' (Muller and Karle 1993: 2).

In essence, the theory predicts that as the level of industrialisation is higher, the effect of family background on children's status positions will be lower, resulting in a transition from ascriptive rules of social mobility to mobility patterns based on personal achievements and meritocratic ideas. The argument that sustains this claim is that the more industrialised societies are, the higher the efficiency of the labour has to be. This will translate into a labour selection mechanism that favours the workers that have optimum preparation for the job, and not the ones that have the best origin. Optimum preparation for the job is secured by a higher level of education and thus education becomes a form of human capital that ensures higher chances to succeed in this market where competences are crucial (Wolbers 2000; DiPrete and Buchman 2006).

In relation to the effect of industrialisation, research has shown that in more developed countries the effect of parents' education on children's educational achievements is less strong than in developing countries (Ganzeboom et al. 1993; Buchmann and Hannum 2001). Also, Kelley and Klein (1981) argued that in the short (but not in the long) run revolutions promote social mobility. These effects might suggest that not only the level of industrialisation, but also the pace of the industrialisation level matters in the transition from ascription to achievement. We can argue that in countries undergoing severe or rapid changes, the whole social system goes through a period of turbulence, where achievement-based rules are not yet fully functioning. In these social systems, family resources might function as a safety net, and their influence in decisions regarding 
education might be augmented instead of being weakened. Concluding, we advance two hypotheses. First, in country-cohorts with higher levels of industrialisation, the effect of parents' level of education on their children's level of education is weaker (Hypothesis 1a). Second, in country-cohorts undergoing rapid changes in levels of industrialisation, the effect of parents' level of education on their children's level of education is stronger (Hypothesis 1b).

However, the body of literature that treats this subject has led to diverging results (Ganzeboom et al. 1991; Muller and Karle 1993; Treiman and Ganzeboom 2000; Sieben and de Graaf 2001): other factors complement industrialisation in shaping patterns of intergenerational educational mobility. In the next subsections we will discuss three of these generic factors: female labour force participation, the organisation and setup of the educational system and the political ideology. With the exception of political ideology, all the other factors can be considered as indicators of a trend towards modernisation and postmodernisation (Inglehart 1997).

\subsection{Female labour force participation}

Kalmijn (1994) concludes that mother's education has always been as important as father's education in influencing their children's educational achievements, for both boys and girls. The author also concludes that mother's high occupational status leads to higher educational achievements of her children compared with an unemployed mother and that mother's employment status leads to a weaker effect of father's education (Kalmijn 1994). ${ }^{1}$ This indicates that the occupational role model provided now by mothers is as important as that traditionally provided by fathers.

As previously stated, we note the fact that the effect of female labour force participation as macro-social characteristic was not tested formally. In their analyses, researchers used measures indicating if mothers have a job during the formative period of the child, but they were not preoccupied to test whether the increased participation of women in the labour market has an influence on the intergenerational transmission of education. We raise several arguments on the interaction between this macro societal characteristic and the effect of parents' education on their children's education.

1. It is beyond the scope of this research to also look more into detail at the gender differences in educational attainment. However, it is for further research to investigate the educational trajectories of boys and girls in the context of a gendered labour market. 
On the one hand, we can argue that within families where both parents are working, the material base of the family improves. A better financial situation of the family will increase the financial resources that can be invested in children's education, leading to longer schooling. In this way, mother's labour force participation gives weight to another dimension of family background in determining children's education, with a possible effect of lowering the influence of parents' education. On the other hand, women's movement from home to the workplace may result in the erosion of traditional statuses and roles of men and women. Traditionally, the father was the main breadwinner and in the centre of the socio-economic model of achievements. Changes in the labour market participation of women led to an erosion of the father's status as role model and main influence in the status attainment process, and led to new occupational aspirations and socio-economical expectations of the children, important 'push' factors of educational achievement (Kalmijn 1994). Also, Buchman and DiPrete (2006) argue that, in the case of the US in the early 1980s, the increasing divorce rate and the greater post-divorce child care responsibilities for women raised the importance of good education, since they increasingly needed to play the role of providers for the family, a role traditionally attributed to men. These factors associated with female labour force participation - new occupational aspirations and the changes in the traditional roles as breadwinners - may act as external incentives for better education, independent of other origin influence. As a result, the most visible effect should be a decrease in the importance of the family background effects on intergenerational educational transmission in periods with higher female labour force participation. Since the education of the parents is a component of family background, we expect to observe a similar pattern in the case of the relation between parents' education and children's education. Therefore, we expect that in country-cohorts with higher female labour force participation, the effect of parents' level of education on their children's level of education to be weaker (Hypothesis 2).

\subsection{Educational system}

Kerckhoff $(1995,2001)$ emphasises the need to address the role of institutional arrangements in social mobility patterns, especially school related factors that, in his opinion, will result in a more elaborated conceptualisation of Blau and Duncan's status attainment model. He notes that: 'It is not clear at this point whether there is a systematic association between the observed patterns of social mobility and the variations in institutional arrangements discussed here, but that is an important possibility worthy of careful study' (Kerckhoff 1995: 343). Buchmann 
and Hannum (2001) note that researchers have shown a preoccupation with the 'family versus school' debate, that led to approaches that mainly look at each type of the factors and do not examine how family resources and school systems characteristics interact. In their review, the authors show that characteristics that were found to be insignificant in the case of more developed countries have a significant impact on educational achievements in developing ones. For instance, while in the US research has shown that the quality of schools or per pupil expenditure in education have little impact on educational achievements, this is not the case in developing countries (Buchmann and Hannum 2001). It is thus important to also look at the characteristics of school systems when examining intergenerational mobility between countries and cohorts that are in different stages of development.

Little has been done to explicitly address the relationship between quality of education and family background influences on educational achievements. Heyneman and Loxley (1983) present evidence in this respect, showing that the poorer the country, the greater the impact of school and teacher quality on educational achievements. The authors conclude that in the poorer countries "the educational "push" which children feel from their homes is not as tightly determined by the education or occupation of the parent' (Heyneman and Loxley 1983: 1183) but instead, school quality (basic material inputs such as textbooks, libraries, other facilities, teacher training) prevails in explaining educational achievements. We argue that in countries and periods with lower educational system quality, an increase in the quality of education provided can lower the strains on the family resources invested in children's schooling, thus prolonging the educational career. Therefore, we expect the effect of parents' level of education on their children's level of education to be weaker in country-cohorts with higher educational quality: higher educational expenditure (Hypothesis $3 a$ ) and lower pupilteacher ratio (Hypothesis 3b).

The fact that nation states, through educational policies, can increase the demand for education, independent of the effects of family background, was already documented (Fuller and Rubinson 1992). One of these policies is the compulsory years of schooling and its constant increase in time is registered for all countries. We argue that the family background influence on children's level of education is expected to cover the entire period of schooling, but, in the context of an increasing number of compulsory years of education, this influence will decrease. This is due to the fact that the state takes over part of the decision on what the minimum of education should be, and leaves families no choice but to comply with it. Therefore, we expect that the effect of parents' level of 
education on their children's level of education to be weaker in countrycohorts with longer compulsory schooling (Hypothesis 3c).

A special type of school system characteristic is the accessibility of the educational infrastructure. Frenette (2004) finds support for the idea that increased distance to school is associated with lower university attendance and a larger tendency to attend the local college. This relationship is found to be much stronger in lower-income families. This relates to the problem of the economic cost of education, in terms of transport or accommodation, which is higher when the educational units are further from home and less accessible. Ballarino et al. (2009) showed that in Spain an improvement in transport made it possible for boys and girls from marginal, difficult-to-reach rural villages to go on to further education. Thus, the higher the accessibility of the school infrastructure, the lower the strain on the family resources will be when investing in children's education. As a result, the origin's impact on children's educational achievements should be weaker. Although education is not a perfect indicator of family income, evidence indicates that the higher educated have more resources, financial and non-financial, than the lower educated (Harmon et al. 2003). Consequently, our hypothesis reads as follows: the higher the accessibility of the educational infrastructure, the weaker is the effect of parents' level of education on their children's level of education (Hypothesis 3d).

\subsection{Political ideology}

The interest in the effect of the political structure on the patterns of social mobility has emerged in the work of the first generation of social mobility research (Ganzeboom et al. 1991). One of the main topics of research in this area, which constantly re-emerged in the work of the social mobility researchers, is the analysis of the impact of communist and socialdemocratic regimes in shaping patterns of intergenerational educational mobility (Ishida et al. 1995; Ganzeboom and Nieuwbeerta 1999; Sieben and de Graaf 2001; Sieben and Huinink 2001). However, evidence suggests that the reforms of social-democratic and communist states which are supposed to increase educational opportunities and promote higher social mobility did not fulfil their goal. Nevertheless, tests of these assumptions were not rigorously conducted in a comparative setting. In essence, theory suggests that the social-democratic and communist state policies will lead to higher access and equality of educational opportunities. This would result in lowering educational inequalities between classes and facilitate upward intergenerational educational mobility. Therefore, we formulate the following, and last, hypothesis: in country- 
cohorts with social-democratic and communist regimes, the effect of parents' level of education on their children's level of education is weaker (Hypothesis 4).

\section{Data and methods}

For information on individual-level characteristics, we used data from the three waves of the European Social Survey (ESS); the first was conducted in 2002, the second in 2004, and the third in 2006. The ESS is an academically-driven multi-country survey covering over 30 countries and is designed and carried out to exceptionally high standards. It involves strict random probability sampling, a minimum target response rate of 70 percent and rigorous translation protocols. All persons aged 15 and over, resident within a private household, regardless of their nationality, citizenship, language or legal status could be asked to participate in a face-to-face interview (Jowell 2003, 2005, 2007). ${ }^{2}$

In the sample, we only incorporated those countries which did not have incompatibilities in key variables, listed on the website of the ESS. Furthermore, Turkey was excluded from the analysis, because it had a disproportionate influence on the estimates. ${ }^{3}$ In total, 28 countries were analysed. In order to be sure that all respondents included in the analysis had theoretically finished their formal education, we only selected those over the age of 25 .

\subsection{Measurement of educational attainment}

In order to have a reliable measurement of education that can be compared across countries, we used 'the virtual years of education', as proposed by Ganzeboom and Treiman (1994) and used by Sieben and de Graaf (2001), which measures the minimum number of years it takes to complete a certain educational level. Because our aim is not to estimate the strength of the relation between parents' education and their children's educational achievements, but to estimate how this relationship is influenced by contextual characteristics, we looked at education as a unitary process and did not differentiate between access to different levels of education as

2. For more information on the ESS, please refer to http://www. europeansocialsurvey.org/ where the data and documentation is freely available to download.

3. We used the Cook Distance and the SDbeta's in order to estimate the influence on the total estimates and parameter estimates separately. By excluding Turkey, the total estimates became more stable. 
separate social processes. Moreover, in this way our models are more parsimonious.

We recoded the original country specific ISCED classification into the minimum years of education. Detailed information on the structure of the educational system provided by Eurydice was used (The structure of... 2009) to recode the country specific ISCED classification into the minimum cumulative years needed to complete a certain educational level. For Switzerland, the Russian Federation, Israel and Ukraine there was no information available on the structure of the educational system by Eurydice. Therefore, descriptions of national educational departments were used.

The educational attainment of the parents is recoded correspondingly. For the parsimony of the model, we decided to use the highest educational level of either parent. Previous research showed that the mother's role is much the same as that of the father (Kalmijn 1994; Korupp et al. 2002; Marks 2008). Regarding the fact that parents do not usually share exactly the same level of education, analyses showed that the higher educated parent explains most of the variance of children's education (Korupp et al. 2002), while the lower educated parent still has a significant effect. Therefore, we conclude that, while both parents' education matters when explaining their children' education, the most important effect is that of the parent with the highest educational attainment. ${ }^{4}$ We selected only the families where information on both parents' educational attainment is available.

\subsection{Contextual characteristics}

We enriched our data with contextual characteristics. For that purpose, we computed five-year birth cohorts for each country separately. Because there were no respondents in the latest cohorts for Italy and Israel, these cohorts are excluded, which results in 250 country-cohort combinations. The included macro characteristics are measured from 1950 to 1996, with the lower limit only due to the lack of data availability. We computed for each respondent an average of the macro characteristics as it was registered during the period when he or she was between 12 and 15 years old. We used this interval, because in most countries it overlaps with the end of compulsory education, a period when decisions about future educational trajectories are made. In order to obtain the value of each contextual

4. We also tested models where there was a distinction made between the education of the father and the mother, but the effects were the same. Therefore we decided to opt for the more parsimonious model. 
characteristic for each of the 250 country-cohort combinations, we aggregated the individual values at the second level of the analysis. For nominal variables, the modal value of that country-cohort was used.

In order to measure the degree of industrialisation of a certain countrycohort, several measures are included. First, as a measure of the level of industrialisation, we use the gross domestic product per capita (measured in US dollars, 1990). These data mostly come from Historical Statistics of the World Economy: 1-2006 AD dataset. ${ }^{5}$ This variable is introduced in the analysis after a natural logarithmic transformation. Data for Luxemburg and Iceland are derived from Maddison (2001: 179). Second, the change of the employment rate in the tertiary sector is added. The most important part of the information came from the World Bank (2007), the OECD (2009), the International Labour Organization (1990) and the United States Bureau of Labour Statistics (2007). Data for former USSR states were derived from Facts and Figures Annual (1977, 1990, 1991, 1992).

The female labour force participation is measured using the percentage of women of the total active labour force. Data were derived from the World Bank (2007), United States Bureau of Labour Statistics (2007) and the International Labour Organization (1990).

The political ideology of a country-cohort is measured by a dummy variable, which has the value 1 when, in a certain year, either a socialdemocratic or a communist regime was in power, and 0 otherwise. Data was derived from the Kim-Fording Government Ideology database (2002) that contains information on the political ideology of the government starting in some cases from 1945 for almost all the countries in our dataset. For the years there was no data available, we looked for information on election results - party's seats in government through time - and coded the particular parties' ideologies.

In order to determine the quality of the educational system, several indicators are used. First, the educational expenditure of the government as the percentage of the GDP per capita is taken into account. Second, the pupil-teacher ratio is included. This indicates the number of pupils at primary schools, divided by the number of teachers at primary schools. In this case, a higher value indicates that there are more pupils per teacher, which implies a lower educational quality. Third, the school kilometres ratio is added. This indicator measures the number of primary schools divided by the square kilometres of a country. When this ratio is higher, there are more schools per square kilometre which indicates a high

5. For more information on the Historical Statistics of the World Economy: 1-2006 AD dataset, please refer to http://www.ggdc.net/maddison/ where the data and documentation is freely available to download. 
accessibility. Fourth, the compulsory years of education are taken into account. All these indicators are derived from UNESCO (1968-1999) which provides chronological retrospective information from 1950 onwards. However, for the compulsory years of education, there was no information available before 1968. Therefore, additional information from the United Nations (1950-1968) was used.

\subsection{Missing data}

The main problem when collecting contextual data was the fact that the measures were not available in one single database. Most databases on measures on industrialisation or female labour force participation did not contain information prior to 1980 . Also, there were hardly any data available for the former communist countries. In order not to lose a significant part of our sample - namely, countries-cohorts from 1950 to 1980 and former communist countries - we decided to use other available data sources, as described in the rest of the section.

For the former communist countries, when they were not included in the previous mentioned data sources, data of USSR Facts and Figures Annual (1977, 1990, 1991, 1992) were used. When there were still large gaps, mean values of the region were used as estimation. For Estonia and Ukraine, missing data were replaced with data from the USSR. For Slovakia and Slovenia, information for, respectively, Czechoslovakia and Yugoslavia were used. In case of the educational expenditure, the data of the former USSR were restrained in the old yearbooks of UNESCO and reported very high expenditures, whereas in more recent yearbooks, these figures were adjusted. Therefore, we decided to adjust the old numbers with the discrepancy known of recent numbers. Missing data for Switzerland, regarding the pupil-teacher ratio and the school kilometres ratio, were replaced with the mean values of all countries. Remaining missing yearly information was imputed using cubic interpolation for each country separately. When there was only information available from 1960 on, these figures were used as a starting point for the imputations.

\section{Analysis and model testing}

For the purpose of our analysis, missing data on individual level characteristics (age, gender and education of the respondent or the parents) were deleted listwise. We ended up with a workable dataset of 76,821 respondents, covering 250 country-cohort combinations. In order to be able to compare the effects of the various factors of interest, we 


\begin{tabular}{lcccc}
\hline & $N$ & Range & Mean & $\begin{array}{c}\text { Standard } \\
\text { deviation }\end{array}$ \\
\hline Children's education & 76,821 & $0.00-19.00$ & 11.93 & 3.51 \\
& & & & \\
Parents' education & 76,821 & $0.00-19.00$ & 9.64 & 4.44 \\
Male & 76,821 & $0.00-1.00$ & 0.47 & 0.50 \\
& & & & \\
GDP per capita & 250 & $7.42-10.04$ & 8.99 & 0.55 \\
Change in employment service sector & 250 & $-0.43-2.68$ & 0.62 & 0.43 \\
Female labour force participation & 250 & $17.04-51.15$ & 37.80 & 8.34 \\
Educational expenditure & 250 & $0.73-8.79$ & 4.68 & 1.60 \\
Pupil teacher ratio & 250 & $9.41-51.10$ & 22.04 & 6.61 \\
School kilometre ratio & 250 & $0.00-0.30$ & 0.07 & 0.06 \\
Compulsory years of education & 250 & $6.76-12.00$ & 9.55 & 1.06 \\
Social-democratic and communist regime & 250 & $0.00-1.00$ & 0.53 & 0.50 \\
\hline
\end{tabular}

Data source: European Social Survey, 2002-2006 (own calculations).

standardised all non-dichotomous variables (with the exception of the dependent variable), which implies that they all have a mean of 0 and a standard deviation of 1 . Descriptive statistics of all variables with its original metric can be found in Table 1.

\subsection{Explaining variation in the intergenerational transmission of education}

In order to test our hypotheses, we estimated a multi level linear regression analysis for the education of the respondent dependent upon the education of the parents and country-cohort characteristics. This analysis allows simultaneous modelling of individual-level and countrycohort characteristics and their interactions. The goodness-of-fit statistics for each of these models, along with the variance components, are presented in Table 2. Improvements of the model fit are indicated by the difference in the $\log$ likelihood statistic, which follows a chi-squared distribution with degrees of freedom equal to the number of additional parameters estimated.

We first estimated an empty model with only an intercept, without allowing for variation at the second level. Next, we estimated a model that also incorporates country-cohort level variation in the intercept (Model 1). As shown in Table 2, allowing for variance at the second level strongly improved the fit of the model. In the second model, the educational level 
TABLE 2. Different multi-level models of children's education

\begin{tabular}{|c|c|c|c|c|c|c|c|}
\hline & Model & -2 Log likelihood & $\Delta-2$ Log likelihood & $\Delta d f$ & $\sigma_{O j}$ & $\varepsilon_{O i j}$ & $\sigma_{2 j}$ \\
\hline Intercept (individual-level variation) & 0 & 410967.592 & & & & 12.327 & \\
\hline+ Random variation at country-cohort level & 1 & 390255.817 & 20711.775 & 1 & 2.939 & 9.279 & \\
\hline + Parents' education and male & 2 & 374492.300 & 15763.517 & 2 & 1.018 & 7.579 & \\
\hline + Contextual characteristics & 3 & 374395.268 & 97.032 & 8 & 0.681 & 7.579 & \\
\hline + Random slope parents' education & 3a & 373100.668 & 1294.600 & 1 & 0.619 & 7.419 & 0.253 \\
\hline+ Interaction effects & 4 & 372988.059 & 112.609 & 8 & 0.527 & 7.419 & 0.139 \\
\hline
\end{tabular}

Data source: European Social Survey, 2002-2006 (own calculations).

Note: $\sigma_{\mathrm{oj}}$, country-cohort variation; $\varepsilon_{\mathrm{o} i j}$, individual level variation; $\sigma_{2 j}$, random slope variation. 
of the parents is included, along with gender as a control variable. By including these individual variables, it can be determined to what extent compositional differences between country-cohorts can explain variation at the second level. In the third model, the county-cohort characteristics are included in the analysis, which only slightly improved the fit of the model. Next, we allowed the slope of the level of education of the parents to vary across country-cohorts. As a result, the model improved significantly. Finally, in the last model we tested for cross-level interactions in order to explain the variation in the slopes.

Regarding our first research question, we can conclude that there is significant variation of the effect of the parents' level of education on their children's education across countries and cohorts, by looking at the difference in $-2 \log$ likelihood between Models 3 and $3 \mathrm{a}$. This difference is substantially higher than when introducing the contextual characteristics, with only one degree of freedom compared to eight. Therefore, not taking into consideration the variation of the effect of parents' education would be a misspecification of the model.

\section{Results}

In Table 3, the parameter estimates and the variance components of the multi level models are presented step-by-step in order to have a more detailed look on the mechanisms behind the changes. In Model 1, we started with an empty random intercept model to assess the variance components at the individual and the country-cohort level, ${ }^{6}$ which resulted in an intra-class correlation of 0.24 .

In Model 2, the effects of the educational level of the parents and gender, as a control variable, are presented. This model shows that the parents' education has a positive effect on their children's education; if the parents' education increases with one standard deviation, the education of their children increases by 1.607 years. Furthermore, men have a small (0.081), but significantly higher educational level than women. The variance components of Model 2 indicate that the included variables explain 18 percent of the variation at the first level and 65 percent at the second level. This means that a large part of the variation at the second level can be attributed to compositional effects, most probably due to the increase in the level of education between cohorts.

6. Although we did not hypothesise influence on the country level, we also ran models with three levels of analysis (individuals [level 1] nested in country-cohorts [level 2] and country-cohorts nested in countries [level 3]). This three-level analysis only showed slightly different results. 
TABLE 3. Multilevel linear regression analysis of children's education ( $\left.N_{\text {respondents }}=76,821, N_{\text {country-cohorts }}=250\right)$

\begin{tabular}{|c|c|c|c|c|c|c|c|c|}
\hline & \multicolumn{2}{|c|}{ Model 1} & \multicolumn{2}{|c|}{ Model 2} & \multicolumn{2}{|c|}{ Model 3} & \multicolumn{2}{|c|}{ Model 4} \\
\hline & $B$ & $S E$ & $B$ & $S E$ & $B$ & $S E$ & $B$ & $S E$ \\
\hline Parents' education & & & $1.607 * *$ & 0.012 & $1.602 * *$ & 0.012 & $1.602 * *$ & 0.043 \\
\hline Gross domestic product (GDP) & & & & & $0.369 * *$ & 0.080 & $0.350 * *$ & 0.071 \\
\hline Change in the tertiary sector & & & & & -0.055 & 0.055 & -0.074 & 0.050 \\
\hline Female labour force participation & & & & & $0.141 *$ & 0.082 & 0.107 & 0.073 \\
\hline Educational expenditure & & & & & $0.279 * *$ & 0.076 & $0.229 * *$ & 0.068 \\
\hline Pupil teacher ratio & & & & & $0.164 *$ & 0.093 & $0.156 *$ & 0.083 \\
\hline School kilometre ratio & & & & & -0.097 & 0.067 & -0.080 & 0.060 \\
\hline Compulsory years education & & & & & 0.085 & 0.065 & 0.039 & 0.058 \\
\hline Social-democratic and communist regime & & & & & $0.329 * *$ & 0.122 & $0.266 * *$ & 0.110 \\
\hline Parents' education * GDP & & & & & & & $-0.225 * *$ & 0.041 \\
\hline Parents' education $*$ Change in tertiary sector & & & & & & & $0.110 * *$ & 0.030 \\
\hline Parents' education * Female labour force participation & & & & & & & $-0.136 * *$ & 0.042 \\
\hline Parents' education * Educational expenditure & & & & & & & $-0.111 * *$ & 0.038 \\
\hline Parents' education $*$ Pupil teacher ratio & & & & & & & $-0.107 * *$ & 0.047 \\
\hline Parents' education $*$ School kilometre ratio & & & & & & & $0.156 * *$ & 0.034 \\
\hline Parents' education * Compulsory years of education & & & & & & & 0.003 & 0.034 \\
\hline Parents' education * Social-democratic and communist regime & & & & & & & -0.049 & 0.063 \\
\hline Male & & & $0.081 * *$ & 0.020 & $0.080 * *$ & 0.020 & $0.074 * *$ & 0.020 \\
\hline Constant & $11.918 * *$ & 0.109 & $11.873 * *$ & 0.066 & $11.729 * *$ & 0.083 & $11.901 * *$ & 0.075 \\
\hline Variance reduction individual level & & & $18 \%$ & & $18 \%$ & & $20 \%$ & \\
\hline Variance reduction country-cohort level & & & $65 \%$ & & $77 \%$ & & $82 \%$ & \\
\hline Variance reduction random slope & & & & & & & $45 \%$ & \\
\hline
\end{tabular}

$\mapsto \quad$ Data source: European Social Survey, 2002-2006 (own calculations).

$* p<0.05 ; * * p<0.01$. 
In Model 3, the contextual characteristics of the country-cohort combinations are included. The estimates reveal that both the GDP, as a measurement of industrialisation level, and the female labour participation of a country-cohort have a positive effect on the educational level of the respondent. When looking at the size of these effects, it can be concluded that the GDP level has the largest influence on the educational achievement. Regarding the educational system, both the educational expenditure and the pupil-teacher ratio have a positive impact on the educational level of the respondent. Model 3 shows that when the educational expenditure of a country-cohort increases with one standard deviation, the educational level increases by 0.279 years. Furthermore, when the pupil-teacher ratio in a country-cohort combination is higher, the educational attainment of the respondent is higher. Concerning the political ideology of a country-cohort, respondents who live either in a social-democratic or a communist regime show a significantly higher education ( 0.329 years) than respondents who belong to a country-cohort which is not characterised by a social-democratic or communist regime. By including the country-cohort characteristics, 77 percent of the variance at the second level can be explained.

In Model 4 the interaction terms between the highest educational level of the parents and the country-cohort characteristics are included. Regarding the industrialisation thesis, all hypotheses are confirmed. First, Model 4 shows that the effect of the education of the parents on their children's education is lower in country-cohort combinations with a high GDP. This finding supports Hypothesis 1a: in country-cohorts with a higher level of industrialisation, the effect of the parents' education on their children's education is weaker. Second, Model 4 shows that the effect of the parents' education on their children's education is stronger in country-cohorts where the change in the tertiary sector, measured as the pace of industrialisation, is higher. This finding implies that not only the degree of industrialisation has an influence, but also the accelerated pace of the developments, as predicted by Hypothesis $1 \mathrm{~b}$. Third, the effect of the parents' education is weaker in country-cohorts with a high female labour participation. This implies that in country-cohorts where more women work, the impact of the parental education on children's education decreases, which is in accordance with Hypothesis 2.

The results of the interactions with relation to the educational system are less in line with our expectations. First, we observe that the effect of parental education is weaker in country-cohorts where the educational expenditure is higher. This signifies that in country-cohorts where the government invests more in their educational system, intergenerational transmission of education is lower. This finding confirms Hypothesis $3 \mathrm{a}$. Second, we see that in country-cohorts where the pupil-teacher ratio is 
higher, the effect of the parents' educational attainment decreases. This result contradicts Hypothesis $3 b$, as a high pupil-teacher ratio was assumed to imply a low educational quality. However, it might as well be an indicator of extremely high accessibility of education, which is not yet adjusted to the equally high demands. Third, the compulsory years of education does not significantly interact with the education of the parents, which contradicts Hypothesis 3c. Fourth, the school kilometre ratio of a country-cohort seems to strengthen the effect of parental education on children's education. However, the effect is opposed to the predicted direction (Hypotheses 3d). We expected that when the accessibility of education was higher, the influence of the parents' education would be lower. However, our results show that when there are more schools per square kilometre, the influence of the parents' education is higher. This could be the case, because when there are more schools in the area, parents can choose the one that they consider best for their children, whereas when the accessibility is lower, parents do not have a choice.

With respect to the political ideology of a country-cohort, there is no significant interaction with the educational level of the parents. Therefore, Hypothesis 4 is not supported by the data.

As previously shown in Table 2, by allowing for a random slope, the model explained 79 percent of the country-cohort level variance. This indicates that the random slope additionally explains 9 percent of the variance at the second level compared to Model 3. By including the interaction terms, the model explains 20 percent of the individual level variance and 82 percent of the country-cohort level variance. Important to mention is that the variance in the random slope is reduced by 45 percent when including cross-level interactions.

\section{Conclusion and discussion}

In this article, we set out to describe and explain the cross-national and cross-temporal relationship between parents' education and their children's educational achievements. Our choice to focus on the intergenerational transmission of education and not address the full status attainment model as developed by Blau and Duncan (1967) is based on the argument that education, through the massive educational expansion that characterises modern societies, is the central factor behind the assumed, increasing intergenerational social mobility. If educational expansion is the driving force to increase intergenerational social mobility in modern societies, this, in particular, should show up in the weakening of the relationship between parents' education and their children's educational achievements. 
Whereas previous research only focused on industrialisation, characteristics of the educational system, political ideology or the changing role of women in society separately, we combined these characteristics and tested them in a multi level setting over country-cohorts. Moreover, where previous research only included a few countries, we tested the proposed hypotheses for 28 different countries and 250 country-cohort combinations. This design allowed us to assess the between country variation in the importance of the macro-societal conditions tested, thus giving the opportunity to provide generalisations from a monocontextual to a multi-contextual perspective. However, a disadvantage of this approach to comparative analysis is that, while detecting the statistical variation of the macro-variables of interest, it relies heavily on how adequate the used measures are. Lack of complete comparative historical data on social and institutional characteristics of interest impose practical limitations related to the measurements available to be used, a problem faced in the present article as well. Nevertheless, the presented empirical analysis revealed some very interesting and convincing results.

First, we found that in highly industrialised country-cohorts, the relationship between parents' education and their children's educational achievements is weaker than in developing country-cohorts. This finding is in accordance with the industrialisation thesis. Moreover, our analysis revealed that in country-cohorts that are rapidly industrialising, the relationship between parents' education and their children's educational achievements is stronger than in country-cohorts where the pace of industrialisation is slower. This is an important specification of the industrialisation thesis, since this distinction has not been taken into account in previous research.

Second, with respect to the degree of the female labour force participation, we found evidence for our hypothesis that in countrycohorts where more women work, the effect of the parents' education on their children's education decreases. This is in line with previous research suggesting that higher involvement of women in the labour market leads to changes in the educational aspirations of their children. These changes might in turn act as push factors for higher educational achievements.

Third, concerning the effects of the educational system, we only found supporting evidence for our hypothesis regarding the educational expenditure. The results supported the hypothesis that in country-cohorts where educational expenditure is higher, the effect of parental education is lower. This suggests that governmental policies can decrease the degree of social inequality in the educational access. We did not find supporting 
evidence for our hypothesis regarding the pupil-teacher ratio. A reason behind this result might be educational expansion; high educational enrolment might not be accompanied by the direct adjustments of the educational system by providing corresponding higher numbers of teachers. Thus, we might have situations where country-cohorts with low as well as high educational system quality have the same pupilteacher ratio. For future research better indicators of educational quality should be considered.

Fourth, we incorporated the political ideology of a country-cohort in our analysis. We expected that social-democratic and communist state policies would lead to higher access and equality of educational opportunities, which would result in increasing intergenerational transmission of education. However, we did not find support for this hypothesis. We found evidence for the assertion that the educational level is higher in social-democratic and communist country-cohorts, but we did not observe a significant interaction with the parental level of education. However, future research is needed to see whether it interacts with other family background characteristics.

Some drawbacks of this article have to be taken into consideration. First, we were not able to include other characteristics of the family background, which might also contribute to a better understanding of the changing relationship between parents' education and their children's educational achievements across cohorts and countries. For example, family income, number of children in the household, and parental cultural capital are likely to explain the relationship between parents' education and their children's education as well. This might also decrease the variance of the slope of the effect of parents' education which leaves less variance for contextual characteristics. Therefore, further investigation in this area is required. Second, due to a lack of data availability, we were unable to include more contextual characteristics, for instance to measure the stratification of the educational system. We expect that not only the compulsory years of education decrease the effect of parental education, but also the structure and choices that are provided by the educational system. For instance, when there are more educational pathways or trajectories available, parents might have a stronger influence on their children's decisions, and stimulate them to opt for the best option.

To conclude, the empirical analysis showed that the industrialisation thesis is the most important explanation of the variation in the relationship between parents' education and their children's educational achievements across countries and cohorts. Not only were all the hypotheses regarding this theory confirmed, but these indicators also 
showed the largest effects. The indicators of the educational system showed mixed results, which suggests that further research in this area is needed.

\section{References}

Ballarino, G., Bernardi, F., Requena, M. and Schadee, H. (2009) 'Persistent inequalities? Expansion of education and class inequality in Italy and Spain', European Sociological Reviem 25: 123-38.

Blau, P. and Duncan, O. D. (1967) The American Occupational Structure, New York: Wiley.

Breen, R. and Jonsson, J. O. (2005) 'Inequality of opportunity in comparative perspective: Recent research on educational attainment and social mobility', Annual Reviem of Sociology 31: 223-43.

Buchmann, C. and DiPrete, T. A. (2006) 'The growing female advantage in college completion: The role of family background and academic achievement', American Sociological Reviem 71: 515-41.

Buchmann, C. and Hannum, E. (2001) 'Education and stratification in developing countries: A review of theories and research', Annual Reviem of Sociology 27: 77-102.

DiPrete, T. A. and Buchmann, C. (2006) 'Gender-specific trends in the value of education and the emerging gender gap in college completion', Demography 43: 1-24.

Frenette, M. (2004) 'Access to college and university: Does distance to school matter', Canadian Public Policy 30: 427-43.

Fuller, B. and Rubinson, R. (1992) The Political Construction of Education, New York: Praeger.

Ganzeboom, H. B. G. and Nieuwbeerta, P. (1999) 'Access to education in six Eastern European countries between 1940 and 1985. Results of a cross-national survey', Communist and Post-Communist Studies 32: $339-57$.

Ganzeboom, H. B. G. and Treiman, D. J. (1994) 'Preliminary results on educational expansion and educational achievement in comparative perspective', in H. A. Becker and P. L. J. Hermkens (eds), Solidarity of Generations, Demographic, Economic and Social Change and its Consequences, Amsterdam: Thesis Publishers, pp. 467-506.

Ganzeboom, H. B. G., Treiman, D. J. and Ultee, W. C. (1991) 'Comparative intergenerational stratification research -3 generations and beyond', Annual Reviem of Sociology 17: 277-302.

Harmon, C., Oosterbeek, H. and Walker, I. (2003) 'The returns to education: Microeconomics', Fournal of Economic Surveys 17: 115-55. 
Heyneman, S. P. and Loxley, W. A. (1983) 'The effect of primary-school quality on academic achievement across twenty-nine high- and lowincome countries', The American Fournal of Sociology 88: 1162-94.

Inglehart, R. (1997) Modernization and Postmodernization: Cultural, Economic, and Political Change in 43 Societies, Princeton, NJ: Princeton University Press.

International Labour Organization (1990) Yearbook of Labour STATISTICS, RETROSPECTIVE Edition, 1945-1989, Geneva: ILO.

Ishida, H., Muller, W. and Ridge, J. M. (1995) 'Class origin, class destination, and education - a cross-national study of 10 industrialnations', American Fournal of Sociology 101: 145-93.

Jaeger, M. and Holm, A. (2007) 'Does parents' economic, cultural, and social capital explain the social class effect on educational attainment in the Scandinavian mobility regime?', Social Science Research 36: 719-44.

Jonsson, J. O. and Mills, C. (1993) 'Social-class and educationalattainment in historical-perspective - a Swedish-English comparison. 1', British Fournal of Sociology 44: 213-47.

Jowell, R. and the Central Co-ordination Team (2003) European Social Survey 2002/2003: Technical Report, London: Centre for Comparative Social Surveys, City University.

Jowell, R. and the Central Co-ordination Team (2005) European Social Survey 2004/2005: Technical Report, London: Centre for Comparative Social Surveys, City University.

Jowell, R. and the Central Co-ordination Team (2007) European Social Survey 2006/2007: Technical Report, London: Centre for Comparative Social Surveys, City University.

Kalmijn, M. (1994) 'Mothers occupational-status and children's schooling', American Sociological Reviem 59: 257-75.

Kelley, J. and Klein, H. S. (1981) Revolution and the Rebirth of Inequality: A Theory Applied to the National Revolution in Bolivia, Berkeley, CA: University of California Press.

Kerckhoff, A. C. (1995) 'Institutional arrangements and stratification processes in industrial-societies', Annual Reviem of Sociology 21: 32347.

Kerckhoff, A. C. (2001) 'Education and social stratification processes in comparative perspective', Sociology of Education 74: 3-18.

Kim, H. and Fording, R. C. (2002) 'Government partisanship in Western democracies, 1945-1998', European Fournal of Political Research 41: $165-84$.

Korupp, S. E., Ganzeboom, H. B. G. and Van der Lippe, T. (2002) 'Do mothers matter? A comparison of models of the influence of mothers' and fathers' educational and occupational status on children's educational attainment', Quality E Quantity 36: 17-42. 
Maddison, A. (2001) The World Economy. A Millennial Perspective, Paris: OECD Publishing.

Muller, W. and Karle, W. (1993) 'Social selection in educational-systems in Europe', European Sociological Reviem 9: 1-23.

OECD (2009) 'OECD Statistics Online', OECD, http://www.oecd.org.

Pfeffer, F. T. (2008) 'Persistent inequality in educational attainment and its institutional context', European Sociological Reviem 24: 543-65.

Przeworski, A. and Teune, H. (1970) The Logic of Comparative Social Inquiry, New York: Wiley.

Shavit, Y. and Blossfeld, H. P. (1993) Persistent Inequality. Changing Educational Attainment in Thirteen Countries, Boulder, CO: Westview.

Sieben, I. and de Graaf, P. M. (2001) 'Testing the modernization hypothesis and the socialist ideology hypothesis: A comparative sibling analysis of educational attainment and occupational status', British Fournal of Sociology 52: 441-67.

Sieben, I. and de Graaf, P. M. (2003) 'The total impact of the family on educational attainment - A comparative sibling analysis', European Societies 5: 33-68.

Sieben, I., Huinink, J. and de Graaf, P. M. (2001) 'Family background and sibling resemblance in educational attainment. Trends in the former FRG, the former GDR, and the Netherlands', European Sociological Reviem 17: 401-30.

The Structure of Education Systems from Pre-Primary to Tertiary Education (ISCED 0 - 5) 2007/08/ (2009) EACEA, Eurydice Brussels.

Treiman, D.J. and Ganzeboom, H.B.G. (2000) 'The fourth generation of comparative stratification research', in S. Quah and A. Sales (eds), The International Handbook of Sociology, London: Sage, pp. 123-50.

UNESCO (1968-1999) Statistical Yearbook, Paris: Unesco.

United Nations (1949-1968) Statistical Yearbook: Prepared by the Statistical Office of the United Nations, New York: United Nations.

United States Bureau of Labour Statistics (2007) 'International labor comparisons database', United States Department of Labour, http:// www.bls.gov.

USSR Facts and Figures Annual (1977, 1990, 1991, 1992) Gulf Breeze, FL: Academic International Press

Wolbers, M. H. J. (2000) Effects of level of education on mobility between employment and unemployment in the Netherlands', European Sociological Reviem 16: 185-200.

World Bank (2007) 'World Development Indicators Online', World Bank Group, http://www.worldbank.org. 
Majka van Doorn is a student in the MSc programme Social and Cultural Science, Radboud University Nijmegen, Nijmegen, The Netherlands.

Ioana Pop is a PhD candidate in the Department of Sociology, Tilburg University, Tilburg, The Netherlands.

Maarten H.J. Wolbers is an associate professor in the Department of Sociology, Radboud University Nijmegen, Nijmegen, The Netherlands.

Address for correspondence: Maarten H. J. Wolbers, Department of Sociology, Radboud University Nijmegen, P.O. Box 9104, 6500 HE Nijmegen, The Netherlands.

E-mail:m.wolbers@maw.ru.nl 